\title{
BILINEAR FOURIER MULTIPLIER OPERATORS ON VARIABLE TRIEBEL SPACES
}

\author{
YIN LIU AND JIMAN ZHAO
}

Abstract. In this paper, we prove the boundedness of bilinear Fourier multiplier operators on variable exponent Triebel-Lizorkin spaces.

Mathematics subject classification (2010): 42B15, 42B35.

Keywords and phrases: Variable exponent, bilinear Fourier multiplier operators, Triebel-Lizorkin spaces.

\section{REFERENCES}

[1] E. Acerbi And G. Mingione, Gradient estimates for the $p(x)$-Laplacean system, J. Reine Angew. Math. 584 (2005), 117-148.

[2] A. Almeida And A. Caetano, On 2-microlocal spaces with all exponents variable, Nonlinear Anal. 135 (2016), 97-119.

[3] A. Almeida And A. Caetano, Atomic and molecular decompositions in variable exponent 2microlocal spaces and applications, J. Funct. Anal. 270 (2016), 1888-1921.

[4] A. Almeida, L. Diening And P. HÄstö, Homogeneous variable exponent Besov and TriebelLizorkin spaces, Math. Nachr. 291 (2018), 1177-1190.

[5] A. Almeida And P. HÄstÖ, Besov spaces with variable smoothness and integrability, J. Funct. Anal. 258 (2010), 1628-1655.

[6] P. Baroni, M. Colombo And G. Mingione, Harnack inequalities for double phase functionals, Nonlinear Anal. 121 (2015), 206-222.

[7] Á. BÉNYI AND R. TORRES, Symbolic calculus and the transposes of bilinear pseudodifferential operators, Comm. Partial Differential Equations 28 (2003), 1161-1181.

[8] F. BERNiCOT AND P. GERMAIN, Bilinear oscillatory integrals and boundedness for new bilinear multipliers, Adv. Math. 225 (2010), 1739-1785.

[9] O. V. BESOV, Equivalent normings of spaces of functions of variable smoothness, Priblizh. Differ. Uravn. 243 (2003), 87-95.

[10] O. V. BESOV, Interpolation, embedding, and extension of spaces of functions of variable smooth-ness, Issled. Teor. Funkts. Differ. Uravn. 248 (2005), 52-63.

[11] Z. Birnbaum AND W. ORLICZ, Über die Verallgemeinerung des Begriffes der zueinander konjugierten Potenzen, Studia Math. 3 (1931), 1-67.

[12] L. Chen, G. Lu AND X. Luo, Boundedness of multi-parameter Fourier multiplier operators on Triebel-Lizorkin and Besov-Lipschitz spaces, Nonlinear Anal. 134 (2016), 55-69.

[13] R. R. COIFMAN AND Y. MEYER, On commutators of singular integrals and bilinear singular integrals, Trans. Amer. Math. Soc. 212 (1975), 315-331.

[14] R. R. COIFMAN AND Y. MEYER, Commutateurs d'intégrales singulières et opérateurs multilinéaires, Ann. Inst. Fourier (Grenoble) 28 (1978), 177-202.

[15] D. V. CruZ-Uribe And A. Fiorenza, Variable Lebesgue Spaces, Foundations and harmonic analysis, applied and numerical harmonic analysis, Birkhäuser/Springer, Heidelberg, 2013.

[16] L. Diening, P. Harjulehto And P. Hästö, et al., Lebesgue and Sobolev Spaces with Variable Exponents, Lecture Notes in Mathematics, 2017. Springer, Heidelberg, 2011.

[17] L. Diening, P. HÄSTÖ AND S. RoudenKo, Function spaces of variable smoothness and integrability, J. Funct. Anal. 256 (2009), 1731-1768. 
[18] B. Dong And J. XU, Herz-Morrey type Besov and Triebel-Lizorkin spaces with variable exponents, Banach J. Math. Anal. 9 (2015), 75-101.

[19] D. Drinem, Atomic decomposition of Besov spaces with variable smoothness and integrability, J. Math. Anal. Appl. 389 (2012), 15-31.

[20] J. FAng And J. ZhaO, Variable Hardy spaces on the Heisenberg group, Anal. Theory Appl. 32 (2016), 242-271.

[21] J. FU AND J. XU, Characterizations of Morrey type Besov and Triebel-Lizorkin spaces with variable exponents, J. Math. Anal. Appl. 381 (2011), 280-298.

[22] H. F. Gonçalves, S. D. Moura, And J.S. NeVEs, On trace spaces of 2-microlocal type spaces, J. Funct. Anal. 267 (2014), 3444-3468.

[23] L. GRAFAKOS AND R. TORRES, Discrete decompositions for bilinear operators and almost diagonal conditions, Trans. Amer. Math. Soc. 354 (2002), 1153-1176.

[24] M. IzUKi AND T. NoI, Duality of Besov, Triebel-Lizorkin and Herz spaces with variable exponents, Rend. Circ. Mat. Palermo 63 (2014), 221-245.

[25] H. KempKa, 2-microlocal Besov and Triebel-Lizorkin spaces of variable integrability, Rev. Mat. Complut. 22 (2009), 227-251.

[26] H. KempKA, Atomic, molecular and wavelet decomposition of 2-microlocal Besov and TriebelLizorkin spaces with variable integrability, Funct. Approx. Comment. Math. 43 (2010), 171-208.

[27] H. KEMPKA AND J. VYBÍRAL, A note on the spaces of variable integrability and summability of Almeida and Hästö, Proc. Amer. Math. Soc. 141 (2013), 3207-3212.

[28] H. KeMPKA AND J. VybíRAL, Spaces of variable smoothness and integrability: Characterizations by local means and ball means of differences, J. Fourier Anal. Appl. 18 (2012), 852-891.

[29] O. KovÁČIK AND J. RÁKosníK, On spaces $L^{p(x)}$ and $W^{k, p(x)}$, Czechoslovak Math. J. 41 (1991), 592-618.

[30] H. G. LeOpold, On Besov spaces of variable order of differentiation, Z. Anal. Anwend. 8 (1989), 69-82.

[31] H. G. LEOPOLD, Embedding of function spaces of variable order of differentiation in function spaces of variable order of integration, Czechoslovak Math. J. 49 (1999), 633-644.

[32] Y. LiU, G. Hu AND J. ZHAO, The boundedness of bilinear Fourier multiplier operators on TriebelLizorkin and Besov spaces, Acta Math. Sinica (Chin. Ser.) 60 (2017), 369-382.

[33] Y. LiU AND J. ZHAO, Abstract Hardy spaces with variable exponents, Nonlinear Anal. 167 (2018), 29-50.

[34] W. Luxemburg, Banach function spaces, Thesis, Technische Hogeschool te Delft, 1955.

[35] C. Musealu, T. TAO AND C. ThIELE, Multi-linear operators given by singular multipliers, J. Amer. Math. Soc. 15 (2002), 469-496.

[36] V. NAIBO, On the bilinear Hörmander classes in the scales of Triebel-Lizorkin and Besov spaces, J. Fourier Anal. Appl. 21 (2015), 1077-1104.

[37] E. NAKAI AND Y. SAWANO, Hardy spaces with variable exponents and generalized Campanato spaces, J. Funct. Anal. 262 (2012), 3665-3748.

[38] H. NaKano, Modulared semi-ordered linear spaces, Maruzen Co., Ltd., Tokyo, 1950.

[39] H. NaKAno, Topology of linear topological spaces, Maruzen Co., Ltd., Tokyo, 1951.

[40] T. NoI, Fourier multiplier theorems for Besov and Triebel-Lizorkin spaces with variable exponents, Math. Inequal. Appl. 17 (2014), 49-74.

[41] T. NoI, Trace and estension operators for Besov spaces and Triebel-Lizorkin spaces with variable exponents, Rev. Mat. Complut. 29 (2016), 341-404.

[42] J. TAN AND J. ZhaO, Fractional integrals on variable Hardy-Morrey spaces, Acta Math. Hungar. 148 (2016), 174-190.

[43] H. TRIEBEL, Theory of function spaces, Birkhäuser Verlag, Basel, 1983.

[44] J. VyBíRAL, Sobolev and Jawerth embeddings for spaces with variable smoothness and integrability, Ann. Acad. Sci. Fenn. Math. 34 (2009), 529-544.

[45] H. Wang And Z. LiU, Local Herz-type Hardy spaces with variable exponent, Banach J. Math. Anal. 9 (2015), 359-378.

[46] J. Xu, Variable Besov and Triebel-Lizorkin spaces, Ann. Acad. Sci. Fenn. Math. 33 (2008), 511-522.

[47] J. XU, The relation between variable Bessel potential spaces and Triebel-Lizorkin spaces, Integral Transforms Spec. Funct. 19 (2008), 599-605. 
[48] D. YANG, C. ZhUo AND W. YuAn, Besov-type spaces with variable smoothness and integrability, J. Funct. Anal. 269 (2015), 1840-1898.

[49] D. YANG, C. ZHUO AND W. YUAN, Triebel-Lizorkin type spaces with variable exponents, Banach J. Math. Anal. 9 (2015), 146-202. 